\title{
Morphological and physiological responses to drought stress of European provenances of Scots pine
}

\author{
Akkın Semerci $^{1} \cdot$ Hacer Semerci $^{1} \cdot$ Belma Çalişkan $^{1} \cdot$ Nuran Çiçek $^{2}$ • \\ Yasemin Ekmekçi $^{2} \cdot$ Maurizio Mencuccini $^{3,4}$ (D)
}

Received: 10 May 2016/Revised: 12 September 2016/Accepted: 26 October 2016/Published online: 2 November 2016 (C) The Author(s) 2016. This article is published with open access at Springerlink.com

\begin{abstract}
Increased frequency and intensity of drought episodes as a consequence of current and predicted climatic changes require an understanding of the intra-specific variability in structural and physiological characteristics of forest trees. Adaptive plasticity and genotypic variability are considered two of the main processes by which trees can either be selected or can acclimate to changing conditions. We tested for the relative importance of genotypic variability, phenotypic plasticity and their interaction by comparing the growth and physiological performance of 15 provenances of Scots pine (Pinus sylvestris L.), under two contrasting irrigation regimes. Selected provenances representing the distribution range of the species in Anatolia, Turkey, were contrasted with seed sources spanning the range from Spain to the UK, in Europe. We found a strong latitudinal differentiation among the 15 provenances for survival after drought, largely the result of the higher mortality of some western and central European provenances. Differentiation in diameter and height growth was
\end{abstract}

Handling editor Rainer Matyssek.

Electronic supplementary material The online version of this article (doi:10.1007/s10342-016-1011-6) contains supplementary material, which is available to authorized users.

\footnotetext{
Maurizio Mencuccini

m.mencuccini@ed.ac.uk

1 General Directorate of Forestry, Ankara, Turkey

2 Department of Biology, Faculty of Science, Hacettepe University, Ankara, Turkey

3 ICREA at CREAF, Universitat Autonoma de Barcelona, Barcelona, Spain

4 School of GeoSciences, University of Edinburgh, Edinburgh, UK
}

also clear with the worst provenance coming from Western Europe (UK). Among the Turkish provenances, the more extreme southern high-elevation populations showed greater survival and lower growth rates overall. Differences in growth and survival were related to differences in photosynthetic pigment and nutrient contents and in the photosynthetic efficiency of photosystem II. Plasticity was strongest for growth characters and pigment contents.

Keywords Scots pine - Genotypic variability $\cdot$ Phenotypic plasticity · Provenance selection · Drought - Growth · Photosynthesis

\section{Introduction}

Models of global climatic change predict that drought frequencies and intensities will increase in many regions during this century, as a direct or indirect result of changes in the atmospheric concentrations of greenhouse gases (IPCC 2014). Worldwide reporting of episodes of forest decline or even dieback in the last few decades in response to high temperatures and drought (e.g. Breshears et al. 2005; Allen et al. 2010; Peng et al. 2011) indicates the need to improve our ability to understand, predict and model future tree responses and survival to water deficit. Genetic variability among individuals and populations and adaptive plasticity are two of the main processes by which forest tree species can adjust to a changing climate, but our understanding of these processes is still limited (e.g. Valladares et al. 2014).

Scots pine (Pinus sylvestris L.) has a wide geographical distribution across Eurasia, growing under a large range of environmental conditions. The broad patterns of its differentiation into ecotypes are well known (Rehfeldt et al. 
2002, Shutyaev and Giertych 1997, 2000). Thanks to field provenance trials established during the past century, response functions of Scots pine growth as a function of the latitudes and longitudes of the site of origin and of the plantation site have been identified in two studies (Rehfeldt et al. 2002; Reich and Oleksyn 2008), although their conclusions differ considerably, suggesting the existence of additional unexplained sources of variability. Besides growth, attention has been devoted to describing geographical patterns related to the physiological processes underlying growth. However, understanding of how variability in physiological processes relates to variability in growth across provenances is still limited. Similarly, while across-site variability in height and diameter growth has been characterised for many provenances, much less effort has been devoted to quantifying the plasticity of specific physiological components of growth and, specifically, how plasticity may vary across provenances (the genotype $\times$ environment interaction). This knowledge is essential to help determine a species response to climate change, and especially its response to episodes of drought, whose intensity and frequency are predicted to increase for parts of the distribution of this species during the twentyfirst century (IPCC 2014).

Phenotypic variation has been shown to occur in physiology and growth across populations of Scots pine, for characters such as water use efficiency and resistance to drought-induced embolism (Martínez-Vilalta et al. 2009), leaf-to-sapwood-area ratios (Mencuccini and Bonosi 2001; Martínez-Vilalta et al. 2009; Laforest-Lapointe et al. 2014), wood density (Laforest-Lapointe et al. 2014), specific leaf area and leaf nitrogen content (Oleksyn et al. 2003; Laforest-Lapointe et al. 2014), growth rates (Rehfeldt et al. 2002; Reich and Oleksyn 2008) and growth rhythm (Notivol et al. 2007). In addition to phenotypic variation, traits such as content of the major nutrients and their resorption efficiency, net photosynthesis, leaf dark respiration, water use efficiency, aboveground height and biomass growth have all been found to vary clinally across provenances in common garden trials, primarily in relation to latitude and elevation (e.g. Oleksyn and Bialobok 1986; Reich et al. 1996; Oleksyn et al. 1998, 1999, 2000, 2001, 2003), but also to longitude (Shutyaev and Giertych 2000; Cregg and Zhang 2001), suggesting strong genetic controls of important adaptive traits. However, much of this evidence has been gathered from provenance trials conducted in the central range of the species distribution in Europe (e.g. Poland, Nordic countries, Russia). In contrast, very little is known on the existence of intra-specific differences in leaf physiology and growth regulation among Southern European Scots pine provenances whose health may be declining under periodically intense drought conditions.
Studies of adaptive variation of populations growing at the southern boundary of the distribution of Scots pine are important because these populations could provide a source of genetic material for traits important for survival against the threats of heat and drought (Alía et al. 2001; Hampe and Petit 2005; Taeger et al. 2013). In one summary of data from five trials in Spain, height growth of Spanish populations was generally lower than that of German provenances, although the best Spanish provenances achieved similar rates to the German provenances (Alía et al. 2001). While the information derived from field-based provenance trials is very useful, little can be gained on variability in provenance-specific responses to drought stress without specific experimental manipulations. Provenance comparisons crossed with a controlled water-stress experiment represent therefore a very powerful approach to detect population-level differences in drought susceptibility. In a greenhouse experiment conducted in Germany, provenances from central Italy and Spain were genetically differentiated from populations from central Europe and showed smaller reductions in shoot growth in response to drought conditions and a more plastic behaviour (Taeger et al. 2013, 2015), a result paralleled by a comparison of Spanish rear-edge populations against Finnish front-edge populations in a greenhouse study in Scotland (Matías et al. 2014). In a greenhouse comparison of 12 interior and coastal provenances, central Asian seed sources from dry sites survived longer under drought, grew less, had greater biomass allocation to roots and higher water use efficiency than more mesic central European seed sources, a clinal longitudinal gradient possibly driven by continentality (Cregg and Zhang 2001).

In Scots pine, structural acclimation to drought involving increased biomass allocation to roots relative to shoots (Taeger et al. 2013, 2015; Matías et al. 2014; Seidel and Menzel 2016) is complemented by tight stomatal control of plant transpiration and photosynthesis and regulation of the ratio between leaf and sapwood areas (Mencuccini and Grace 1995; Poyatos et al. 2007; Martínez-Vilalta et al. 2009). Nonetheless, mortality of Scots pine has been observed at the xeric border of its distribution in the Mediterranean area, e.g. at several locations in the Spanish Pyrenees (e.g. Martínez-Vilalta and Piñol 2002; VilàCabrera et al. 2013), in dry alpine valleys (e.g. Bigler et al. 2006; Rigling et al. 2013) and in central Anatolian regions of Turkey (Allen et al. 2010; Güner and Yücel 2015). Scots pine is therefore a suitable model species to study the limits of physiological plasticity and survival capabilities under drought stress. Probability of survival in response to drought is, however, seldom investigated relative to growth. While Cregg and Zhang (2001) could not find any drought-induced variation in mortality rates of $P$. sylvestris seedlings from several Eastern European and Central Asian 
origins, other studies found substantial population differences in survival rates after droughts. In one case (Matías et al. 2014), population-level differences in drought-induced mortality rates were explained by differences in allocation to above- versus below-ground tissues. In a second study (Seidel and Menzel 2016), provenance differences in probabilities of survival after drought were found to remain significant even after accounting for size differences.

To improve our understanding of Scots pine growth and physiological responses to drought stress, we compared survival and growth responses in height and diameter of 15 provenances of Scots pine collected from across Turkey and parts of Europe (Spain, France, Germany, Rumania and UK) and grown under common garden conditions in Turkey. We measured survival rates in $2+0$ year-old seedlings, growth in height and diameter and needle water potentials, an indicator of plant water status. We also determined polyphasic chlorophyll $a$ fluorescence, photosynthetic pigments (chlorophyll, carotenoids) and (microand macro-) nutrient contents as indicators of photosynthetic performance. Because it gives the possibility to rapidly characterise population-level variability in photosystem II performance, chlorophyll fluorescence has been frequently employed to detect intra-specific differences in tree species (e.g. Havaux et al. 1988; Bigras 2005). In combination with the provenance comparison, we conducted a controlled drought experiment over two years to determine the differential susceptibility of the 15 provenances to drought stress. We hypothesised: (1) that survival would vary across the 15 provenances under the prevailing climatic conditions of this Turkish common garden and that it would be reduced in response to drought, and (2) that growth would vary across the 15 provenances and that it would be reduced in response to drought. For both survival and growth, we checked whether significant interactions between provenance $\times$ drought were found. In addition to survival and growth, we also determined leaf pigment and nutrient contents. Consequently, (3) we determined indices of plasticity for all our variables and we tested whether the differences in growth, physiological and biochemical responses to water stress were related to each other and to variables describing the climatic conditions of the site of origin of the provenances.

\section{Materials and methods}

\section{Plant material}

Seeds were obtained locally from Turkey and from several European countries in which Scots pine (Pinus sylvestris L.) grows naturally. A total of 18 provenances were initially assembled, including Norway, Finland and Russia. However, seeds from these three Nordic provenances showed very high mortality on the seedbed and they were therefore excluded from further experimentation, leaving 15 populations. The main features (i.e. country of origin, geographical coordinates and elevation) of these 15 provenances are listed in Table 1. A plot of the distribution of the 15 seed sources (overlain on the map of the natural distribution of Scots pine across Europe and western Asia) is given in Figure S1. A map giving the mean annual temperature at the 15 European sites is given in Figure S2. The two German provenances come from a lowland and an upland seed-registered site (Waldsieversdorf, close to Berlin and upland North East Bavaria), respectively. The British provenance comes from an upland semi-natural seed-registered stand in Scotland (Abernethy), similarly to the French, the Romanian and the two Spanish seed sources. We used the inventory carried out by the General Turkish Directorate of Forestry Trials to obtain seeds of the Turkish provenances. Seeds from other countries were provided by local collaborators in conjunction with the relevant certification documents. In May, the seeds were sown in pots at the Kizılcahamam forest nursery. Initially, three seeds were sown in each pot. After germination, the three seedlings were thinned to one in each container.

\section{Experimental design}

After germination in the nursery, the $2+0$ potted seedlings were transferred to the greenhouse garden of the Central Anatolian Research Directorate $\left(39.93^{\circ} \mathrm{N}, 32.86^{\circ} \mathrm{E}\right)$ in April. Here, the seedlings were arranged over a concrete slab and water stress was applied before the start of the vegetation period by excluding natural rainfall using a removable transparent tarpaulin shelter. A complete randomised factorial design was employed, consisting of 16 replicate plots for each of the 15 provenances, with each plot containing 10 seedlings. The two treatments (control and drought stress) employed a total of 2440 saplings, although the number of monitored seedlings varied depending on the type of measurement.

\section{Quantification of plant drought stress}

To follow the development of the drought throughout the summer of year 1, groups of 10 seedlings randomly selected from across all the provenances were measured at pre-dawn twice a month, for both the well-watered and the drought-stressed treatment, from May to mid-August during year 1 of the experiment. Measurements of plant water status were not carried out during year 2 of the experiment, but the structure of the treatment remained identical over the two years. Shoot water potential was measured at pre- 
Table 1 Origin name and number, country of origin and main physiographic attributes (latitude, longitude, altitude) of the 15 provenances of Scots pine tested in this study

\begin{tabular}{lllllr}
\hline Provenance no. & Country & Origin Name & Latitude $\left(^{\circ}\right)$ & Longitude $\left(^{\circ}\right)$ & Altitude $(\mathrm{m})$ \\
\hline 4 & UK & psySTN4-01SI & $5712 \mathrm{~N}$ & $337 \mathrm{~W}$ & 360 \\
5 & Germany & Waldsieversdorf & $5232 \mathrm{~N}$ & $1403 \mathrm{E}$ & 75 \\
6 & Germany & Erich-Bergen & $5031 \mathrm{~N}$ & $1227 \mathrm{E}$ & 650 \\
7 & Romania & Brasov Mountains & $4601 \mathrm{~N}$ & $2514 \mathrm{E}$ & 550 \\
8 & France & Mont Ventoux & $4410 \mathrm{~N}$ & $0513 \mathrm{E}$ & 1121 \\
9 & Turkey & Vezirköprü-Kunduz & $4109 \mathrm{~N}$ & $3501 \mathrm{E}$ & 1200 \\
10 & Turkey & Ilgaz-Yenice & $4101 \mathrm{~N}$ & $3349 \mathrm{E}$ & 1500 \\
11 & Turkey & Koyulhisar-Sisorta & $4023 \mathrm{~N}$ & $3756 \mathrm{E}$ & 1950 \\
12 & Turkey & Sarkkamiş-Sarıkamiş & $4018 \mathrm{~N}$ & $4237 \mathrm{E}$ & 2350 \\
13 & Spain & Montes universales & $4005 \mathrm{~N}$ & $125 \mathrm{~W}$ & 1342 \\
14 & Turkey & Çatacik-Değirmendere & $3958 \mathrm{~N}$ & $3107 \mathrm{E}$ & 1550 \\
15 & Turkey & Kayseri -Pınarbaş1 & $3843 \mathrm{~N}$ & $3613 \mathrm{E}$ & 1840 \\
16 & Turkey & Akdağmadeni-Çulhalı & $3930 \mathrm{~N}$ & $3552 \mathrm{E}$ & 1750 \\
17 & Spain & Sierra Nevada & $3700 \mathrm{~N}$ & $330 \mathrm{~W}$ & 1700 \\
18 & Turkey & Çamlıdere-Benliyayla & $4031 \mathrm{~N}$ & $3208 \mathrm{E}$ & 1550 \\
\hline
\end{tabular}

dawn using a pressure chamber apparatus (Martínez-Vilalta et al. 2009). Measurements were carried out in several consecutive days each month to obtain sufficient coverage across provenances. Well-watered seedlings were irrigated on alternate days aiming to maintaining a pre-dawn water potential of around $-0.4 \mathrm{MPa}$ (mild drought stress), whereas stressed seedlings were only watered periodically (on average every 10-15 days) aiming to achieve a predawn water potential of around $-1.2 \mathrm{MPa}$ (severe drought stress). The intention was not to obtain an extreme level of drought stress leading to complete plant death, but rather to differentiate the behaviour of the various provenances during extensive dry summer periods while reaching levels of significant mortality for some provenances. Drought stress was applied for four months from May to August over two consecutive years, after which times the rain shelter was removed. Differential mortality occurred throughout the experiment, and survival was monitored as a function of provenance and treatment.

\section{Effects of provenance and drought stress on seedling growth and on needle polyphasic chlorophyll $a$ fluorescence (OJIP)}

Seedling heights $(\mathrm{cm})$ and root collar diameters $(\mathrm{mm})$ were measured for all seedlings once a year at the same time when dead and surviving seedlings were counted for each provenance and for control and drought-stressed treatments ( $n=80$ seedlings nested within eight plots for each provenance and level of treatment).

Polyphasic chlorophyll $a$ fluorescence induction kinetics were measured using a HandyPEA fluorimeter (Plant Efficiency Analyser, Hansatech Ltd., Norfolk, UK) in early August on all seedlings for both control and drought stress treatments ( $n=40$ seedlings nested within four plots for each provenance and level of treatment). Measurements were performed between 10:00 a.m. and 13:00 p.m. after being dark-adapted inside leaf clips for at least $30 \mathrm{~min}$ to ensure completely open reaction centres. A 4-mm-diameter circular portion of the needles was illuminated homogeneously with three light-emitting diodes (LED) providing a pulse of saturating light intensity of $3000 \mu \mathrm{mol} \mathrm{m} \mathrm{m}^{-2} \mathrm{~s}^{-1}$ (650 nm peak wavelength). The chlorophyll fluorescence transients were recorded between $10 \mu \mathrm{s}$ and $1 \mathrm{~s}$ at $12 \mathrm{bit}$ resolution (Strasser et al. 2000). The JIP-test was performed to analyse fluorescence transients. This test, based on energy flux theory for biomembranes in a photosynthetic sample, employs the fluorescence data to derive biophysical parameters that quantify energy flow through PSII (Strasser and Strasser 1995; Strasser et al. 2004). Table S1 lists the phenomenological and biophysical (structural and functional) parameters quantifying the behaviour of photosystems I and II that were employed.

\section{Effects of provenance and drought stress on needle photosynthetic pigment and nutrient contents}

For the pigment content determination, needle samples (approx. $50 \mathrm{mg}$ ) were extracted in $10 \mathrm{~mL}$ of $100 \%$ acetone and centrifuged at $3500 \mathrm{rpm}$ for $5 \mathrm{~min}$. The absorbance of the extracts was measured at 470, 644.8 and $661.6 \mathrm{~nm}$. The contents of chlorophyll (chl) $a, \mathrm{chl} b$ and carotenoids (car, $x+c$ ) were calculated using formulae by Lichtenthaler (1987). The samples for pigment content analysis were collected at the end of the vegetation period ( $n=4$ averages per plot for each provenance and level of treatment). Samples for nutrient content analyses were taken at the end of the vegetation period ( $n=3$ averages per plot for each 
provenance and level of treatment). Contents of $\mathrm{N}, \mathrm{P}, \mathrm{K}^{+}$, $\mathrm{Ca}^{2+}, \mathrm{Mg}^{2+}, \mathrm{Na}^{+}, \mathrm{Fe}^{2+}, \mathrm{Mn}^{2+}, \mathrm{Zn}^{2+}, \mathrm{Cu}^{2+}$ were determined (Bergmann 1992). Nitrogen (N) was determined using the Kjeltec Auto 1030 Analyser device using nitricperchloric acid and the SOMI-micro Kjeldahl method. Phosphate $(\mathrm{P})$ was determined using the yellow vanadamo molibdophosphoric method using a Spectronic 20D colorimetry device. Sodium $\left(\mathrm{Na}^{+}\right)$and potassium $\left(\mathrm{K}^{+}\right)$were determined using PFP 7 Jenway Flame Photometer device. $\mathrm{Ca}^{2+}, \mathrm{Mg}^{2+}, \mathrm{Fe}^{2+}, \mathrm{Cu}^{2+}, \mathrm{Zn}^{2+}$ and $\mathrm{Mn}^{2+}$ were determined in the Perkin-Elmer 3110 atomic absorption spectrometer device.

\section{Estimates of plasticity}

Phenotypic plasticity in response to water stress was estimated for the four main groups of traits (growth, chlorophyll fluorescence, nutrients and pigments) with a logresponse ratio, i.e. by subtracting the logarithm of the population-mean trait value in water-stressed plants from the logarithm of the population-mean trait value in control plants (Hedges et al. 1999). According to this index, positive values of plasticity indicate that population means of control plants are higher than population means of droughtstressed plants. Conversely, negative values indicate higher values for drought-stressed plants. Values of plasticity were calculated for all variables within each group of traits and averaged across. We assumed that plasticity occurred when treatment differences were significant in the corresponding mixed model or ANOVA.

\section{Statistical analyses}

Individual measurements of seedling height, diameter and their respective growth rates were analysed by linear mixed models using provenance, irrigation treatment and their interaction as fixed factors and plot as random factor using the library lme4 (Bates et al. 2015) in R (R Core Team 2015). Chlorophyll fluorescence and nutrient content data were first transformed using principal component analysis (PCA) to reduce the dimensionality of the data before analysis. The resulting eigenvectors were examined for their percent of variance explained, and the first three principal components (PC) were retained for subsequent analysis. PCs extracted from the chlorophyll fluorescence data were analysed using linear mixed models as explained above. PCs extracted from nutrient contents data were analysed by ANOVA using provenance, stress and their interaction as fixed factors and plot averages as replicates. Pigment data were analysed directly using ANOVA as explained above. Survival rates were analysed by ANOVA using treatment and provenance as fixed factors and plot averages as replicates, after arcsin transformation of the proportions. While the analysis was performed on the transformed data, the results are given in the original units. Shoot water potentials were not measured for all provenances simultaneously, and they were analysed using repeated-measures ANOVA using treatment as the fixed factor and the bi-weekly times as the within-treatment repeated measurement variable. Normality of data distribution was checked using a Kolmogorov-Smirnov test and $q-q$ plots of sample versus theoretical distribution quantiles, while variance homogeneity was checked by a Levene test. Tukey contrasts for multiple comparisons of means using simultaneous tests for general linear hypothesis tests were created with the glht package in R (Hothorn et al. 2008). Finally, the significance of latitude, longitude or elevation as covariates together with drought treatment as fixed factors was assessed by using provenance (for pigments and nutrient contents) and provenance with plot nested in provenance (for seedling height, diameter, growth rates and chlorophyll fluorescence variables) as random factors in a mixed model. Differences in plant size caused by provenance and treatment effects could potentially affect the estimated responses to drought and confound our interpretation. Potential effects of plant size were checked by repeating all the above analyses by adding stem volume index (calculated as the product of collar diameter squared and seedling height) as an additional predictor. Because adding plant size (although sometimes significant in itself), did not change either the direction or magnitude of the differences, results without plant size as a predictor are presented here. Climatic information for the 15 seed-collection sites was obtained from WorldClim (Hijmans et al. 2005; http://biogeo.ucdavis.edu/data/climate/worldclim). WorldClim climatic data were employed together with growth increment data in height and diameter, chlorophyll fluorescence, pigments and nutrient contents, to carry out a cross-correlation analysis. All statistical analyses were performed in R ( $\mathrm{R}$ Core Team 2015, R version 3.2.2 (201508-14).

\section{Results}

\section{Effects of the drought stress treatment}

The experiment resulted in different levels of pre-dawn water potentials across the two treatments, i.e. control versus drought. During the summer, the level of stress in the severely drought-stressed seedlings developed gradually reaching a peak of around $-1.5 \mathrm{MPa}$ in pre-dawn water potentials in the treatment in mid-August, whereas the control (mild stress) remained at levels of -0.4 to $-0.5 \mathrm{MPa}$ throughout the summer, as intended (effects for Date and for Treatment $\times$ Date, both $P<0.0001$, Table 2; 
Table 2 Results of the analysis of variance of the differences between drought treatment and the provenances for predawn shoot water potential and seedling survival

\begin{tabular}{lrrl}
\hline Variable & $d f$ & \multicolumn{1}{l}{$F$} & Probability $(P)$ \\
\hline Water potentials & & & \\
Treatment & 1 & 482.31 & $<\mathbf{0 . 0 0 0 1}$ \\
Date & 7 & 87.46 & $<\mathbf{0 . 0 0 0 1}$ \\
Treatment $\times$ Date & 7 & 34.26 & $\mathbf{< 0 . 0 0 0 1}$ \\
Residuals (across) & 18 & & \\
Residuals (within) & 126 & & \\
Survival & & & \\
Treatment & 1 & 489.67 & $<\mathbf{0 . 0 0 0 1}$ \\
Provenance & 14 & 4.07 & $<\mathbf{0 . 0 1}$ \\
Residuals & 14 & & \\
\hline
\end{tabular}

$d f$ Degrees of freedom; $F F$ test; Probability, probability that differences due to the factor are obtained by chance. Significant factors are in bold

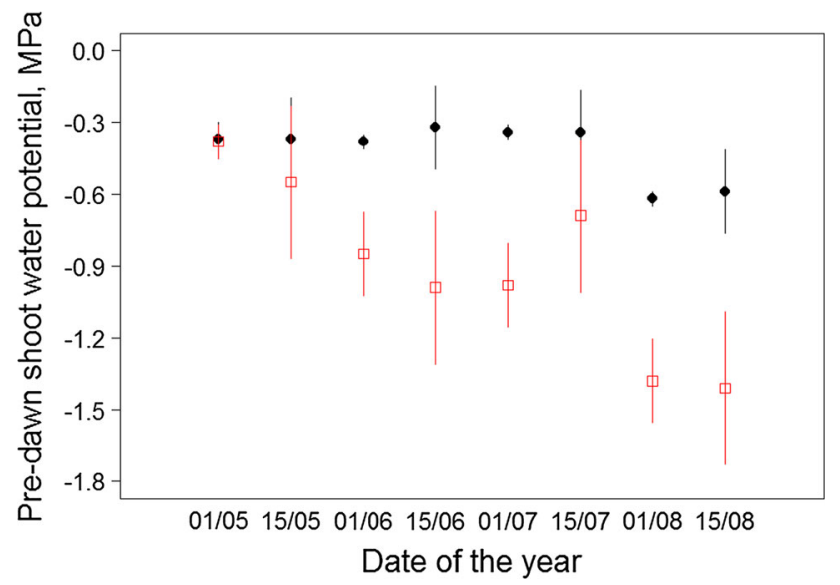

Fig. 1 Changes in shoot pre-dawn water potentials during the first summer of the study for the control (black circles) and the waterstressed (red squares) seedlings of 15 Scots pine populations. Vertical lines are $95 \%$ confidence intervals. (Color figure online)

Fig. 1). The effect of provenance on the level of water stress achieved during the summer could not be tested because of limited replication due to the intensive workload required.

\section{Survival and growth differences across provenances}

Survival varied significantly across the 15 provenances and was also significantly affected by drought treatment $(P<0.01,<0.0001$, respectively, Table 2 ; Fig. $2 \mathrm{a})$. A significant interaction between treatment and provenance was also found $(P<0.0001)$. Treatment and latitude of origin (both $P<0.0001$, Fig. $2 b$ ) were significant factors in affecting survival among provenances. In addition, there was a highly significant interaction between treatment and latitude $(P<0.01)$, with western and Nordic provenances suffering greater mortality during drought than Turkish provenances. When volume index was added as a predictor of survival in addition to treatment and provenance, it was not found to be significant $(P>0.05)$.

All measurements of size and growth, i.e. total height at the end of the second year (Fig. 3a), height growth during the first year, height growth during the second year and collar diameter at the end of the second year (Fig. 3b), varied significantly across provenances (all $P<0.0001$; Table 3). Treatment was significant in explaining variability for some growth parameters (especially, height growth during the first year), while the interaction between treatment and provenance was highly significant for nearly all growth parameters, except for height in the first year $(P>0.05$; Table 3$)$. Mean values of diameter and height for the two years, two treatment levels and 15 provenances are given in Table S2. Variability in diameter, height and diameter/height growth among provenances was unrelated to survival, when examined separately for each treatment $(P>0.05)$, with only one significant correlation (a positive relationship between survival and diameter at the end of the second year for droughted plants, $P=0.04$ ).

\section{Biochemical and physiological differences across provenances and irrigation treatments}

Mean values of all nutrients for the two treatment levels and 15 provenances are given in Table S3. The mean and the range of the macro- and micro-nutrients found across the 15 provenances are compared against reference values taken from the literature in Table S4. Given the number of chemical elements analysed, a principal component analysis (PCA) was carried out on all the nutrient data to reduce dimensionality and ease interpretation. Among the nutrient data, $71 \%$ of the variance of the PCA could be explained by the first four and $61 \%$ by the first three principal components (PC, Table S5). The first PC was related primarily to the micro-nutrients $\mathrm{Ca}, \mathrm{Mg}$ and $\mathrm{Zn}$, the second $\mathrm{PC}$ primarily to $\mathrm{N}, \mathrm{K}$ and $\mathrm{Na}$, whereas the third $\mathrm{PC}$ was primarily a function of $\mathrm{Mn}$ and $\mathrm{Cu}$.

JIP-test parameters calculated from polyphasic chlorophyll fluorescence (OJIP) transients were used to evaluate the effects of water stress on photosynthetic activity. To reduce the dimensionality of the data-set and ease interpretation, a PCA was carried out also on these data. The first three principal components (PC) of the PCA explained about $74 \%$ of the variance (Table S6). PC1 was primarily a function of variables related to the maximum quantum yield of PSII and the combined performance of light energy absorption and conversion to electron transport (i.e. $F_{\mathrm{v}} / F_{\mathrm{m}}$ or $\mathrm{TR}_{0} / \mathrm{ABS}, \varphi_{\mathrm{Eo}}$ or $\mathrm{ET}_{0} / \mathrm{ABS}, \varphi_{\mathrm{Do}}$ or $F_{0} / F_{\mathrm{M}}$, and $\left.\mathrm{PI}_{\mathrm{abs}}\right)$ 


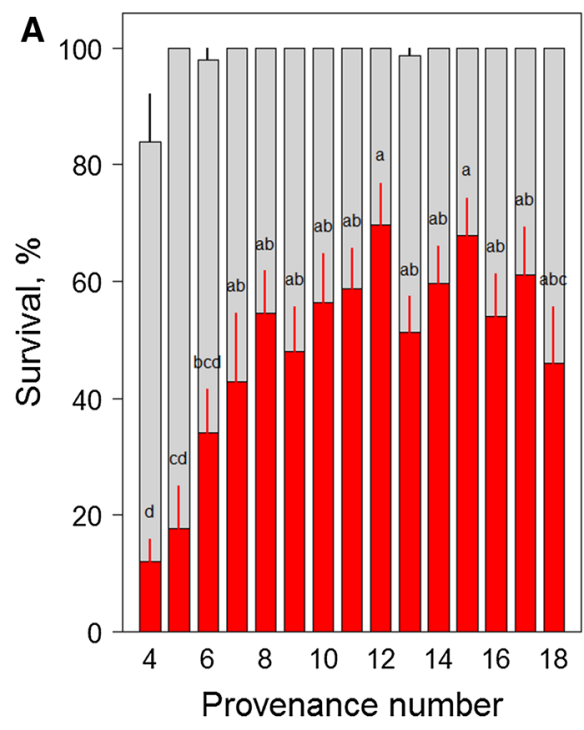

Fig. 2 a Changes in survival rates of 15 provenances of Scots pine collected from across Europe after 2 years of growth in a common garden. Values for the plants in the control treatment are in light grey colour, whereas values for plants in the drought treatment are in red. Vertical bars are one standard error, and letters above the bars indicate differences among provenances based on Tukey contrasts for multiple comparisons using simultaneous tests. The UK group (provenance \#4) was the worse with a survival of $12 \%$, whereas the provenance from Sarıamıs (Turkey, \#2) was the best with a

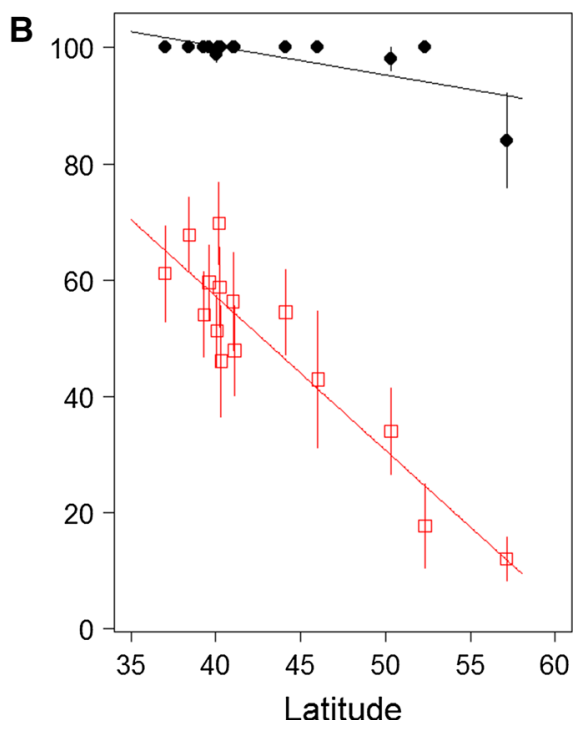

maximum of $69.7 \%$. b Regression of percent plant survival after 2 years of growth in a common garden for plants grown under low water stress (black circles and line) and under medium water stress (red squares and lines). Drought treatment and latitude of origin were very highly significant factors in an ANOVA test (both $P<0.0001$ ), while the interaction term was highly significant $(P<0.01)$. Vertical lines give one standard error of the estimate. The adjusted $R^{2}$ for the complete model was 0.97 . (Color figure online)
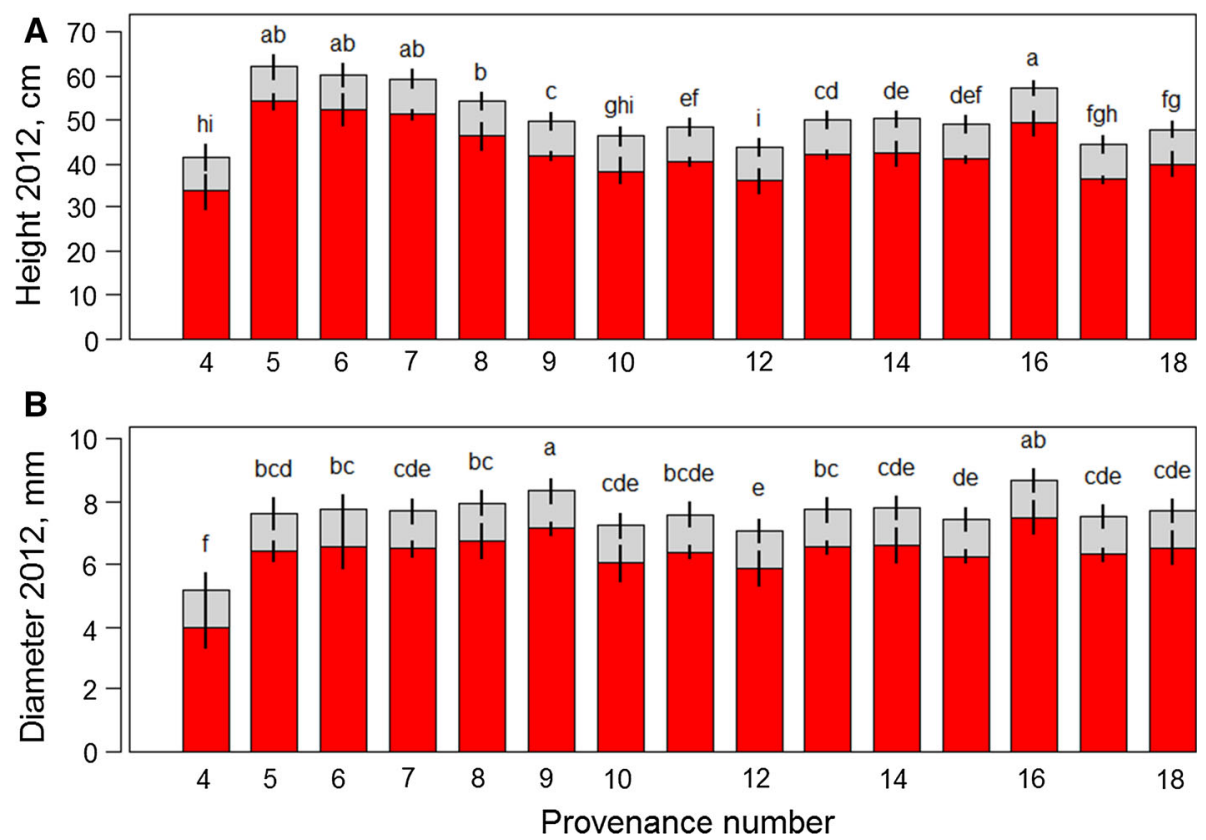

Fig. 3 Top panel changes in height after 2 years of a common garden trial in 15 provenances of Scots pine collected from across Europe and subject to two drought treatments. Bottom panel root collar diameter in the second year of the study. Values for the plants in the control treatment are in light grey colour, whereas values for plants in the drought treatment are in red. Vertical bars are $95 \%$ confidence intervals. Letters above the bars give groupings based on Tukey contrasts for multiple comparisons using simultaneous tests. The interaction term between treatment and provenance was highly significant $(P<0.001)$. (Color figure online) 
Table 3 Results of the analysis of variance of the differences between drought treatment and the provenances for various growth variables

\begin{tabular}{|c|c|c|c|}
\hline Variable & $d f$ & $F$ & Probability $(P)$ \\
\hline \multicolumn{4}{|l|}{ Height end of first year } \\
\hline Treatment & 1 & 0.33 & $>0.05$ \\
\hline Provenance & 14 & 1474.37 & $<0.0001$ \\
\hline Provenance $\times$ Treatment & 14 & 1.50 & $>0.05$ \\
\hline Residuals & 1501 & & \\
\hline \multicolumn{4}{|l|}{ Height end of second year } \\
\hline Treatment & 1 & 3.61 & $<0.10$ \\
\hline Provenance & 14 & 527.81 & $<0.0001$ \\
\hline Provenance $\times$ Treatment & 14 & 3.61 & $<0.001$ \\
\hline Residuals & 1501 & & \\
\hline \multicolumn{4}{|l|}{ Diameter in second year } \\
\hline Treatment & 1 & 2.89 & $<0.10$ \\
\hline Provenance & 14 & 246.88 & $<0.0001$ \\
\hline Provenance $\times$ Treatment & 14 & 2.26 & $<0.01$ \\
\hline Residuals & 1501 & & \\
\hline \multicolumn{4}{|l|}{ Height increment first year } \\
\hline Treatment & 1 & 5.09 & $<0.05$ \\
\hline Provenance & 14 & 1854.33 & $<0.0001$ \\
\hline Provenance $\times$ Treatment & 14 & 2.25 & $<0.01$ \\
\hline Residuals & 1501 & & \\
\hline \multicolumn{4}{|c|}{ Height increment second year } \\
\hline Treatment & 1 & 0.14 & $>0.05$ \\
\hline Provenance & 14 & 34.54 & $<0.0001$ \\
\hline Provenance $\times$ Treatment & 14 & 3.46 & $<0.0001$ \\
\hline Residuals & 1501 & & \\
\hline
\end{tabular}

Values in bold under probability indicate variance terms significant to at least $P<0.05$

$d f$ Degrees of freedom, $F F$ test; Probability, probability that differences due to the factor are obtained by chance

(Table S7). PC2 was primarily a function of variables expressed per unit of cross section (i.e. $\mathrm{ABS} / \mathrm{CS}_{0}, \mathrm{TR}_{0} / \mathrm{CS}_{0}$, $\mathrm{ET}_{0} / \mathrm{CS}_{0}$, and $\mathrm{RC} / \mathrm{CS}_{0}$ ). Finally, PC3 was primarily a function of flux variables expressed per unit of reaction centre (i.e. $V_{\mathrm{J}}, V_{\mathrm{I}}, S_{\mathrm{m}}, \Psi_{0}$ or $\mathrm{ET}_{0} / \mathrm{TR}_{0}, \mathrm{ABS} / \mathrm{RC}, \mathrm{TR}_{0} / \mathrm{RC}$, $\mathrm{ET}_{0} / \mathrm{RC}, \mathrm{DI}_{0} / \mathrm{RC}$ and $R_{\mathrm{e}} / \mathrm{RC}$ ) (Table S7).

Highly significant differences across provenances were detected for many of the chlorophyll fluorescence $(P<0.001,<0.05$, and $<0.001$, for PC1, PC2 and PC3, respectively), nutrients $(P<0.10,<0.01,>0.05$, for PC1, PC2 and PC3, respectively) and pigment variables (i.e. all $P<0.0001$ for chlorophyll $a$, chlorophyll $b$ and for total carotenoids; Table 4). Treatment level differences were significant for some components of chlorophyll fluorescence (PC1, $P<0.0001$ ), nutrients (only PC3, $P<0.05$ ) and for both chlorophyll and total carotenoids $(P<0.01$, $<0.10$ and $<0.0001$, respectively). Significant provenance by treatment interactions was also found for many physiological and biochemical variables (Tables 3 and 4). To check whether differences in plant size affected these outcomes, these analyses were repeated by including stem volume index as a covariate. None of the conclusions reached in Table 4 changed, i.e. when differences among provenances were significant, their effect remained significant when stem volume index was added as a predictor. Similarly, with one exception (PC1 of the chlorophyll fluorescence analysis), the effect of treatment remained significant, if it was already significant before adding stem volume index. Finally, stem volume index was generally not significant for chlorophyll fluorescence and nutrients, but was always significant for pigments (with larger plants having more diluted pigment contents).

\section{Variability in needle chlorophyll fluorescence variables, pigments and nutrient contents as a function of geographical variables}

The first three principal components of the PCA for the JIP-test parameters were regressed against treatment, longitude, latitude and elevation in various combinations as fixed factors in a mixed effect model accounting for origins as a random factor. PC1 showed strong significant effects for elevation $(F$ value $=6.71, P<0.01)$, whereas PC2 and PC3 did not. Latitude and longitude were also tried but were never found to be significant. For PC1, changes in the most important variables, i.e. $\varphi_{\mathrm{Do}}\left(F_{0} / F_{\mathrm{m}}\right)$ and $\left[\varphi_{\mathrm{Po}} /\right.$ $\left(1-\varphi_{\mathrm{Po}}\right)$ ], suggested higher values of maximal photochemical efficiency of PSII for the control relative to the drought treatment and for higher elevation provenances relative to lower elevation ones.

Regarding nutrient contents, a significant effect for longitude was found for PC1 $(F=4.29, P<0.05)$ and PC2 $(F=3.47, P<0.05)$. Latitude and elevation were also tried with all three PCs but were never found to be significant. Considering the pigments, significant effects were found for both longitude and elevation when regressed against chlorophyll $a$ ( $F$ value for longitude $=6.69$, $P<0.01 ; F$ value for elevation $=12.12, P<0.01)$. Similar results were also found for chlorophyll $b,(a+b),(a /$ $b)$ and carotenoids $(P<0.05$ only for this last variable). Overall, both longitude and latitude affected needle nutrient and pigment contents, but their effects varied depending on the particular set of variables considered.

\section{Overall relationships among growth, physiological, geographical and climatic variables}

Diameter and height measurements for the two measurement years (i.e. absolute diameter and height, height growth increments for both years) were significantly related to both elevation and latitude of the origin (data not 
Table 4 Results of mixedmodel (for chlorophyll fluorescence) or analysis of variance (for nutrients and pigments) for the differences caused by drought treatment and provenance

\begin{tabular}{|c|c|c|c|c|c|c|c|c|c|}
\hline \multirow{2}{*}{\multicolumn{2}{|c|}{$\begin{array}{l}\text { Variable } \\
\text { Chlorophyll fluorescence } \\
\mathrm{PC} 1\left(F_{\mathrm{v}} / F_{\mathrm{m}}, \varphi_{\text {Eo }}, \varphi_{\text {Do }}, \mathrm{PI}_{\mathrm{abs}}\right)\end{array}$}} & \multirow[t]{2}{*}{$F$} & \multirow[t]{2}{*}{ Prob $(P)$} & \multicolumn{3}{|c|}{ Nutrients } & \multicolumn{3}{|c|}{ Pigments } \\
\hline & & & & \multicolumn{3}{|c|}{$\mathrm{PC} 1(\mathrm{Ca}+\mathrm{Mg}+\mathrm{Zn})$} & \multicolumn{3}{|c|}{ Chlorophyll $a$} \\
\hline Treatment & 1 & 15.77 & $<0.0001$ & 1 & 0.13 & $>0.05$ & 1 & 8.90 & $<0.01$ \\
\hline Provenance & 14 & 2.71 & $<0.001$ & 1 & 3.67 & $<0.10$ & 1 & 6.13 & $<0.0001$ \\
\hline Provenance $\times$ Treatment & 14 & 1.51 & $<0.10$ & 1 & 0.05 & $>0.05$ & 1 & 2.87 & $<0.01$ \\
\hline Residuals & 1770 & & & 87 & & & 105 & & \\
\hline $\begin{array}{l}\text { Variable } \\
\text { Chlorophyll fluorescence }\end{array}$ & $d f$ & $F$ & Prob $(P)$ & $\begin{array}{l}d f \quad F \\
\text { Nutrien }\end{array}$ & $\begin{array}{l}F \\
\text { nts }\end{array}$ & $\operatorname{Prob}(P)$ & $\begin{array}{l}d f \\
\text { Pigme }\end{array}$ & & Prob $(P)$ \\
\hline \multicolumn{4}{|c|}{$\mathrm{PC} 2\left(\mathrm{ABS} / \mathrm{CS}_{0}, \mathrm{TR}_{0} / \mathrm{CS}_{0}, \mathrm{ET}_{0} / \mathrm{CS}_{0}, \mathrm{RC} / \mathrm{CS}_{0}\right)$} & \multicolumn{3}{|c|}{$\mathrm{PC} 2(\mathrm{~N}+\mathrm{K}+\mathrm{Na})$} & \multicolumn{3}{|c|}{ Chlorophyll $b$} \\
\hline Treatment & 1 & 2.40 & $>0.05$ & 1 & 0.05 & $>0.05$ & 1 & 3.30 & $<0.10$ \\
\hline Provenance & 14 & 1.86 & $<0.05$ & 1 & 2.75 & $<0.01$ & 1 & 6.62 & $<0.0001$ \\
\hline Provenance $\times$ Treatment & 14 & 2.10 & $<0.01$ & 1 & 0.95 & $>0.05$ & 1 & 2.76 & $<0.01$ \\
\hline Residuals & 1770 & & & 87 & & & 105 & & \\
\hline $\begin{array}{l}\text { Variable } \\
\text { Chlorophyll fluorescence }\end{array}$ & $d f$ & $F$ & Prob $(P)$ & & $\begin{array}{c}F \\
\text { Itrients }\end{array}$ & $\operatorname{Prob}(P)$ & $\begin{array}{l}d f \\
\text { Pigm }\end{array}$ & $\begin{array}{l}F \\
\text { ents }\end{array}$ & Prob $(P)$ \\
\hline $\begin{array}{l}\mathrm{PC} 3\left(V_{\mathrm{J}}, V_{\mathrm{I}}, S_{\mathrm{m}}, \Psi \mathrm{o}, \mathrm{ABS} / \mathrm{H}\right. \\
\left.R_{\mathrm{e}} / \mathrm{RC}\right)\end{array}$ & C, TRo & $/ \mathrm{RC}, \mathrm{ET}$ & $\mathrm{o} / \mathrm{RC}, \mathrm{DIo} / \mathrm{RC}$ & & $3(\mathrm{Mn}$ & $+\mathrm{Cu})$ & Caro & enoids & \\
\hline Treatment & 1 & 0.00 & $>0.05$ & 1 & 5.46 & $<0.05$ & 1 & 15.48 & $<0.0001$ \\
\hline Provenance & 14 & 3.55 & $<0.001$ & 1 & 1.13 & $>0.05$ & 1 & 4.58 & $<0.0001$ \\
\hline Provenance $\times$ Treatment & 14 & 1.88 & $<0.05$ & 1 & 1.19 & $>0.05$ & 1 & 4.38 & $<0.0001$ \\
\hline Residuals & 1770 & & & 87 & & & 105 & & \\
\hline
\end{tabular}

Values in bold under probability indicate variance terms significant to at least $P<0.05$

$d f$ Degrees of freedom, F F test, Prob probability that differences due to the factor are obtained by chance. For chlorophyll fluorescence and nutrients, test results are given for the first three principal components of a principal component analysis. For pigments, results are given separately for chlorophylls $a, b$ and total carotenoids. Variables contributing most to each PCA are listed in brackets. Tests significant at least at $P<0.05$ are given in bold; tests significant at $P<0.10$ are given in italics shown). The strongest correlations were found between absolute height at the end of first year and elevation $(P=0.01$, negative sign $)$ and between height growth and latitude ( $P=0.02$, positive sign). The shape of these correlations was often curvilinear (data not shown), with broad maxima for latitudes between $40^{\circ}$ and $45^{\circ} \mathrm{N}$, i.e. slightly further North than the latitude of our field trial (i.e. $40^{\circ} \mathrm{N}$ ).

Finally, a pairwise correlation analysis was carried out to help interpret the relationships among survival, growth, photosynthetic parameters estimated by chlorophyll fluorescence, pigments, needle nutrient contents and climate at the sites of origin of the provenances. Using average data for each provenance and each of the two treatments (i.e. $n=15$ each), survival and all measures of diameter and diameter growth correlated negatively with an index of precipitation during the driest quarter of the year at the site of origin (Fig. 4). Height in 2011 and 2011 and height growth for both years during the second year showed moderate correlations with temperature of the wettest month at the site of origin in both control and droughted plants (Fig. 4, all $P<0.01$ ), but survival did not. Besides climate at the site of origin, significant relationships were found between provenance variability in growth and provenance chlorophyll fluorescence, pigment and needle nutrient contents (Fig. 4). Significant but weaker relationships were found between several growth parameters and some of the photosynthetic parameters estimated via polyphasic chlorophyll fluorescence transients for both control and drought treatments ( $n=15$ each). The most important correlations were found between diameter and height in second year and the PC2 and PC3 of polyphasic chlorophyll fluorescence transients. These relationships were explored in more details and were found to reflect the relationships between height in second year with $\varphi_{\text {Do }}\left(F_{0} /\right.$ $\left.F_{\mathrm{m}}\right)(r=-0.50, P<0.01)$, diameter in second year and $F_{\mathrm{v}} / F_{0}(r=0.55, P<0.01)$, and between height growth in second year and $\varphi_{\text {Po }}\left(\left(F_{\mathrm{v}} / F_{\mathrm{M}}\right.\right.$ or $\left.\mathrm{TR}_{0} / \mathrm{ABS}\right)(r=0.50$, $P<0.01)$, i.e. with indices of maximal photochemical efficiency of photosystem II. None of the correlations were in the expected direction, i.e. they indicated lower photosynthetic efficiency in the faster growing provenances and in the drought relative to the control treatment. 


\section{Estimates of plasticity}

Estimates of plasticity varied depending on the particular group of traits considered (Table 5). Plasticity was highest and positive for growth $(0.34 \pm 0.01)$, indicating significantly larger values in control plants. Relatively large and negative values of plasticity were also found for the pigments $(-0.14 \pm 0.06)$, indicating significantly larger values in drought-stressed plants. Plasticity values for chlorophyll fluorescence and nutrients were more variable and generally lower and not significantly different from zero $(0.02 \pm 0.01$ and $0.02 \pm 0.02$, respectively), corresponding with the lack of significance of treatment in the ANOVAs of many of the principal components of these two groups of traits.

\section{Discussion}

\section{Variability in survival among provenances and in response to treatment}

Several comparative studies of provenance-level variability in leaf physiology have been carried out in trees (e.g. Havaux et al. 1988; Reich et al. 1996; Oleksyn et al. 2003;
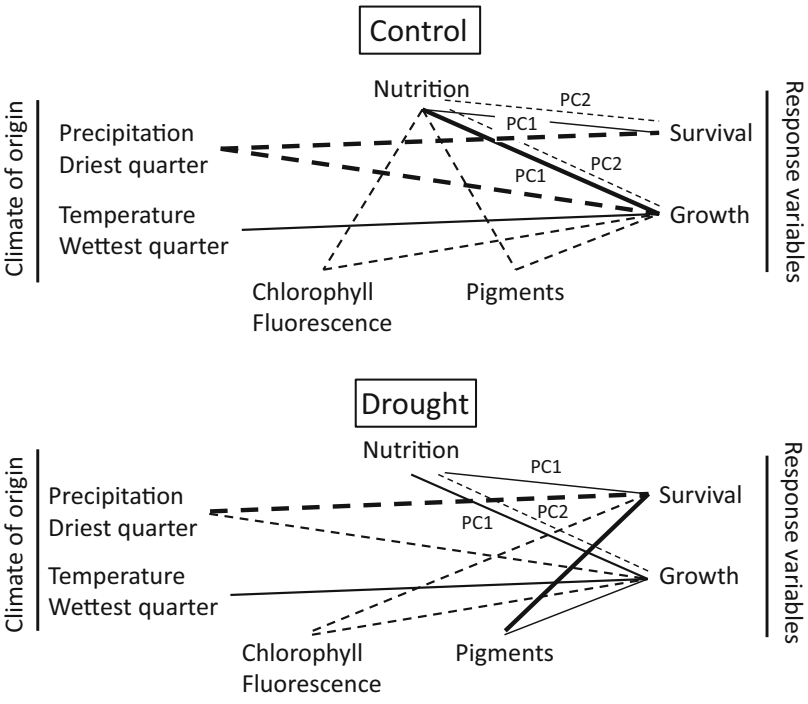

Fig. 4 Pairwise correlations between mean climatic variables (from WorldClim) across 15 Scots pine provenances sampled across Europe, pigments, chlorophyll fluorescence, nutrient and two response variables, survival and growth. Only significant relationships are depicted. Dashed lines indicate negative relationships, and solid lines positive relationships. For each group of traits, correlations were calculated for each variable within each group, and hence thick lines reflect the occurrence of both highly significant and numerous correlations. For nutrition, PC1 (principal component 1) gave positive correlations with growth, whereas PC2 gave negative correlations. Correlations were calculated for the 15 provenances separately for the control (top) and the drought (bottom) treatments
Bigras 2005). However, only a few have examined the interaction of intra-specific genetic variability with other stress factors, such as drought (in Scots pine, Taeger et al. 2013, 2015; Matías et al. 2014; Seidel and Menzel 2016). Our drought stress treatment was carried out with the objective of exposing plants to a period of prolonged water stress. Significant mortality took place during the first year of the experiment, especially in some of the provenances from more westerly and northerly latitudes. A strong relationship was found between survival at the end of the first year and latitude of origin of the provenances (Fig. 2). Survival appeared to be significantly worse in northern provenances and especially after the application of the drought stress treatment, suggesting that the environmental conditions of the common garden in Turkey were very challenging for that material. Our correlation analysis (Fig. 4) showed that survival was negatively related with precipitation of the driest quarter of the year at the site of origin, for both control and drought treatments, consistent with the fact that mortality rates were highest for provenances typical of wetter central European sites. Under drought conditions, high chlorophyll $a$ and $b$ contents were also strongly and positively related to survival.

\section{Variability in growth among provenances and in response to treatment}

Genetically controlled differences among provenances were found for all four groups of variables examined in this work, i.e. growth, chlorophyll fluorescence, nutrients and pigments (Tables 3,4). These differences were robust to incorporating plant size as an additional explanatory variable, suggesting that provenance-related differences in size did not explain our results. Interestingly, the effects of the covariate plant volume index were most significant for the pigment variables (with more diluted contents in larger plants), but were generally unimportant for chlorophyll fluorescence and nutrients. The robustness of the provenance differences reported here to the effects of plant size confirms the existence of significant genetic variability for these characters in Scots pine (e.g. Alía et al. 2001; Cregg and Zhang 2001, Oleksyn et al. 1998, 1999, 2000, 2001, 2003).

In Scots pine, seed mass varies systematically across latitude with significantly larger seeds in southern provenances (Reich et al. 1994). The variability in seed mass across provenances can have carry-over effects on absolute seedling height, with these effects being strongest for 1-year-old seedlings but lasting for several years. We did not standardise our seed selection to avoid systematic differences in average seed mass across provenances; therefore, some of the differences in height that we observed may have been due to this effect. However, the seed mass effect 
Table 5 Phenotypic plasticity estimates for the key variable groups measured in this experiment (growth, chlorophyll fluorescence, nutrients and pigments) in response to water availability

\begin{tabular}{llrrr}
\hline Provenance No. & Growth & Chlorophyll fluorescence & \multicolumn{1}{l}{ Nutrients } & \multicolumn{1}{l}{ Pigments } \\
\hline 4 & $0.31( \pm 0.19)$ & $0.07( \pm 0.04)$ & $0.06( \pm 0.18)$ & $0.44( \pm 0.19)$ \\
5 & $0.68( \pm 0.09)$ & $-0.02( \pm 0.10)$ & $-0.11( \pm 0.11)$ & $-0.46( \pm 0.09)$ \\
6 & $0.39( \pm 0.11)$ & $-0.07( \pm 0.03)$ & $-0.09( \pm 0.08)$ & $-0.29( \pm 0.05)$ \\
7 & $0.52( \pm 0.09)$ & $0.00( \pm 0.05)$ & $0.00( \pm 0.17)$ & $-0.34( \pm 0.10)$ \\
8 & $0.31( \pm 0.11)$ & $0.06( \pm 0.03)$ & $0.02( \pm 0.19)$ & $-0.21( \pm 0.07)$ \\
9 & $0.37( \pm 0.13)$ & $0.03( \pm 0.03)$ & $0.12( \pm 0.07)$ & $-0.14( \pm 0.06)$ \\
10 & $0.26( \pm 0.16)$ & $0.03( \pm 0.04)$ & $0.02( \pm 0.10)$ & $-0.20( \pm 0.05)$ \\
11 & $0.22( \pm 0.11)$ & $-0.01( \pm 0.04)$ & $0.05( \pm 0.10)$ & $-0.20( \pm 0.07)$ \\
12 & $0.24( \pm 0.11)$ & $0.01( \pm 0.04)$ & $0.11( \pm 0.07)$ & $0.14( \pm 0.04)$ \\
13 & $0.25( \pm 0.11)$ & $0.01( \pm 0.07)$ & $0.02( \pm 0.13)$ & $0.07( \pm 0.07)$ \\
14 & $0.29( \pm 0.13)$ & $0.07( \pm 0.03)$ & $0.12( \pm 0.12)$ & $-0.21( \pm 0.05)$ \\
15 & $0.24( \pm 0.05)$ & $0.01( \pm 0.04)$ & $-0.03( \pm 0.11)$ & $-0.17( \pm 0.10)$ \\
16 & $0.35( \pm 0.15)$ & $0.01( \pm 0.04)$ & $0.05( \pm 0.09)$ & $-0.22( \pm 0.05)$ \\
17 & $0.24( \pm 0.06)$ & $0.00( \pm 0.03)$ & $0.01( \pm 0.10)$ & $-0.27( \pm 0.09)$ \\
18 & $0.37( \pm 0.13)$ & $0.06( \pm 0.04)$ & $-0.05( \pm 0.19)$ & $-0.07( \pm 0.13)$ \\
Overall mean & $\mathbf{0 . 3 4}( \pm 0.01)$ & $\mathbf{0 . 0 2}( \pm 0.01)$ & $\mathbf{0 . 0 2}( \pm 0.02)$ & $-\mathbf{0 . 1 4}( \pm 0.06)$ \\
\hline
\end{tabular}

Plasticity estimates are given separately for each provenance and as an overall mean. Positive values of plasticity indicate that trait values were higher under control (mild water stress) conditions. Negative values of plasticity indicate that trait values were higher under the treatment (severe water stress) conditions

Values in bold under probability indicate variance terms significant to at least $P<0.05$ observed by Reich et al. (1994) affected absolute heights, not height growth, as expected if seed mass primarily has a carry-over effect from early availability of stored reserves. However, our strongest correlations with environmental factors were indeed with height growth (data not shown). It is unlikely therefore that the latitudinal trends we observed could be explained entirely by seed mass effects, a point reinforced by the significant correlations observed between height and diameter growth rates and maximal photochemical efficiency of photosystem II, PC1 and PC2 of the nutrient variables and with some of the pigments (Fig. 4). Finally, some of the Turkish provenances with presumably large seed mass had low growth rates.

Variability in diameter, height and height growth among the provenances was correlated with latitude, and sometimes also elevation of the site of origin. When we examined the correlation between growth parameters and climatic variables extracted from WorldClim, height growth during year 2 showed a very strong and positive correlation with temperature of the wettest month and a strong negative correlation with precipitation of the driest quarter of the year (Fig. 4). In studies carried out in field trials located in central lowland Europe, growth in height and biomass of lowland provenances has been found to be curvilinearly related to latitude, with peak values for the provenances sampled close to the field trial site (e.g. Oleksyn et al. 1998, 1999, 2000). In our case, curvilinear relationships with latitude were also found, but the peak was shifted South, around $45^{\circ} \mathrm{N}$. Our significant positive correlation between height growth and temperature of the wettest month also contrasts with the finding from central lowland Europe, where generally positive correlations between shoot growth and temperature failed to represent faithfully the behaviour of southern Turkish populations (e.g. Oleksyn et al. 2001). The direction of the correlations of height growth against temperature of the wettest month and precipitation of the driest quarter of the year suggest that the central European provenances employed in our trial did not fare well under the high evaporative conditions experienced in the common garden, whereas the best performing populations, especially under drought conditions, were those that came from the warmest Turkish sites. Differences in growth rates were also apparent among the Turkish provenances. The existence of significant strong variability among Turkish provenances confirms earlier results on small seedlings obtained by Tilki (2005) who studied seed germination and the first phases of radicle growth under the effect of drought stress induced by polyethylene glycol. The southernmost provenances from that trial (which was also represented in this trial) showed reduced susceptibility to water stress by having higher percent germination rates and higher radicle growth at high levels of water stress. Similar conclusions were also reached by Kulac et al. (2015) after drought conditioning and field transplanting of two-year-old Scots pine seedlings in Turkey. 
Estimates of plasticity and correlations between growth, physiological and biochemical variables

Besides genetically controlled provenance differences, we also found significant treatment effects for many of the study variables, suggesting significant phenotypic plasticity in response to the imposed drought treatment. Quantitative estimates of plasticity varied greatly among the four groups of variables and, for each group, for individual traits (Table 5). As expected, growth metrics were highly plastic, followed by traits related to pigments. Although chlorophyll fluorescence and nutrients showed little plasticity as a group, individual variables showed much higher plasticity, e.g. for some of the chlorophyll fluorescence performance indices and $\mathrm{Cu}, \mathrm{Mn}$ and $\mathrm{N}$ contents. Overall, physiological and biochemical variables were less plastic then growth, suggesting that additional unmeasured processes contributed to the overall growth responses to drought. Nonetheless, growth co-varied with changes in physiological and biochemical variables. Height growth during the second year was strongly and positively correlated with needle micro-nutrients such $\mathrm{Ca}^{2+}, \mathrm{Mg}^{2+}$ and $\mathrm{Zn}^{2+}$. In trials conducted in Central Europe, growth variability across Scots pine provenances was also strongly related to needle nutrient contents. Northern provenances planted at a lowland Polish site (covering the range from 45 to $60^{\circ} \mathrm{N}$ ) had higher $\% \mathrm{~N}$ and higher rates of needle dark respiration compared to provenances from central lowland and Southern Europe (Reich et al. 1996). We did detect a significant relationship between rates of growth and needle $\% \mathrm{~N}$, as present in PC2 of the nutrient PCA. However, this relationship was weak and not in the expected direction. At our southern Turkish site, nutrient deficiencies may have determined the poor performance of central European provenances by restricting leaf area growth and leading to accumulation of $\mathrm{N}$ and pigments in poorly growing genotypes (cf., Güner and Yücel 2015).

Growth variables (diameter, height and height growth) in the second year were also significantly correlated with photosynthetic parameters from chlorophyll fluorescence, especially the maximum quantum yield of PSII, $F_{\mathrm{v}} / F_{\mathrm{m}}$. The direction of the correlations implied that photochemical efficiency of PS II significantly declined during drought stress for all provenances, with regressions within each treatment also significant. The occurrence of significant differences in photosynthetic efficiency across the 15 provenances is consistent with the fact that we also detected significant differences among provenances in nutrition and in photosynthetic pigments (especially, chlorophyll $a$ ).

The strong responses of all growth variables, JIP-test parameters and needle photosynthetic pigments to the irrigation regimes suggest that Scots pine can adjust plastically at least some of its physiological parameters to drought (Mencuccini and Grace 1995; Martínez-Vilalta et al. 2009; Taeger et al. 2015). For several of the growth, physiological and biochemical parameters, significant genotype $\times$ environment interactions were found, suggesting that plasticity in response to drought has a strong genetic component in Scots pine photosynthetic and growth physiology. Future investigations using Turkish provenances could explore the existence of significant family-level variability in the same characters to allow understanding whether adaptive plasticity occurs also within populations. Given the importance of hydraulic architecture in the response to drought of forest trees (Mencuccini and Grace 1995; Martínez-Vilalta et al. 2009), investigation of these variables is also recommended.

\section{Conclusions}

Our results showed a strong differentiation in performance among the provenances examined here, which included local autochthonous origins from Turkey and provenances western and central Europe. The majority of the differences detected in survival were attributable to the lower performance of the German, French, and especially the English, provenances, whereas growth of German provenances was generally very high. Turkish provenances also showed significant differences among one another with the more extreme southern and high-elevation populations more resistant to drought-induced mortality and characterised by low growth rates. Survival at the end of the second year of the trial was related to latitude of origin. Subsequent differentiation in diameter and height growth showed that variability in growth across provenances and treatments was associated with differences in longitude, with the climate of the site of origin and, physiologically, with indices of nutrient and photosynthetic performance. Variability in nutrients across provenances was reduced and the plasticity of the nutrient response to the drought stress treatment was even more limited, whereas pigments (and partly photosynthetic performance) responded strongly to the treatment. Given the reduced variability in nutrition across provenances, it is possible that additional physiological traits not quantified in this experiment were partly responsible for the high variability in performance across provenances. Scots pine is known to vary greatly its hydraulic architecture as a function of the climate of the site of origin. It is possible therefore that a significant genetic component also exists for the hydraulic architecture of this species. Future studies should concentrate on these aspects. 
Acknowledgements The General Directorate of Forestry of Turkey provided support for this project to AS. MM was supported by UK NERC Grant NE/I011749/1.

Open Access This article is distributed under the terms of the Creative Commons Attribution 4.0 International License (http://crea tivecommons.org/licenses/by/4.0/), which permits unrestricted use, distribution, and reproduction in any medium, provided you give appropriate credit to the original author(s) and the source, provide a link to the Creative Commons license, and indicate if changes were made.

\section{References}

Alía R, Moro-Serrano J, Notivol E (2001) Genetic variability of Scots pine (Pinus sylvestris) provenances in Spain: growth traits and survival. Silva Fenn 35:27-38

Allen CD, Macalady AK, Chenchouni H, Bachelet D, McDowell N, Vennetier M, Kitzberger T, Rigling A, Breshears DD, Hogg EH et al (2010) A global overview of drought and heat-induced tree mortality reveals emerging climate change risks for forests. For Ecol Manag 259:660-684

Bates D, Maechler M, Bolker BM, Walker SC (2015) Fitting linear mixed-effects models using lme4. J Stat Softw 67:1-48

Bergmann W (1992) Nutritional disorders of plants: development, visual and analytical diagnosis. G. Fisher, New York, NY

Bigler C, Bräker OU, Bugmann H, Dobbertin M, Rigling A (2006) Drought as an inciting mortality factor in Scots pine stands of the Valais, Switzerland. Ecosystems 9:330-343

Bigras FJ (2005) Photosynthetic response of white spruce families to drought stress. New For 29:135-148

Breshears DD, Cobb NS, Rich PM, Price KP, Allen CD, Balice RG, Romme WH, Kastens JH, Floyd ML, Belnap J, Anderson JJ, Myers OB, Meyer CW (2005) Regional vegetation die-off in response to global-change-type drought. PNAS USA 102:15144-15148

Cregg BM, Zhang JW (2001) Physiology and morphology of Pinus sylvestris seedlings from diverse sources under cyclic drought stress. For Ecol Manag 154:131-139

Güner ST, Yücel E (2015) The relationships between growth of Pinus sylvestris ssp. hamata forests with ecological factors in Central Anatolia. Biol Div Conserv 8:06-19

Hampe A, Petit RJ (2005) Conserving biodiversity under climate change. The rear edge matters. Ecol Lett 8:461-467

Havaux M, Ernez M, Lannoye R (1988) Tolerance of poplar (Populus sp.) to environmental stresses. I. Comparative study of poplar clones using the in vivo chlorophyll fluorescence method. Acta Oecol 9:161-172

Hedges LV, Gurevitch J, Curtis PS (1999) The meta-analysis of response ratios in experimental ecology. Ecology 80:1150-1156

Hijmans RJ, Cameron SE, Parra JL, Jones PG, Jarvis A (2005) Very high resolution interpolated climate surfaces for global land areas. Int J Climatol 25:1965-1978

Hothorn T, Bretz F, Westfall P (2008) Simultaneous inference in general parametric models. Biom J 50:346-363

IPCC (2014) Climate change 2014: impacts, adaptation, and vulnerability. Part A: global and sectoral aspects. Contribution of Working Group II to the Fifth Assessment Report of the Intergovernmental Panel on Climate Change. Cambridge University Press, Cambridge, UK

Kulac S, Turna I, Çiçek E, Sağlam A, Taşdemir Ü (2015) Early field performance of drought-stressed Scots pine (Pinus sylvestris L.) seedlings. Pak J Bot 47:1317-1324
Laforest-Lapointe I, Martínez-Vilalta J, Retana J (2014) Intraspecific variability in functional traits matters: case study of Scots pine. Oecol 175:1337-1348

Lichtenthaler HK (1987) Chlorophylls and carotenoids: pigments of photosynthetic membranes. Method Enzym 148:350-382

Martínez-Vilalta J, Piñol J (2002) Drought-induced mortality and hydraulic architecture in pine populations of the NE Iberian Peninsula. For Ecol Manag 161:247-256

Martínez-Vilalta J, Cochard H, Mencuccini M, Sterck F, Herrero A, Korhonen JFJ, Llorens P, Nikinmaa E, Nolè A, Poyatos R et al (2009) Hydraulic adjustment of Scots pine across Europe. New Phytol 184:353-364

Matías L, González-Díaz P, Jump AS (2014) Larger investment in roots in southern range-edge populations of Scots pine is associated with increased growth and seedling resistance to extreme drought in response to simulated climate change. Environ Exp Bot 105:32-38

Mencuccini M, Bonosi L (2001) Leaf/sapwood area ratios in Scots pine show acclimation across Europe. Can J For Res 31:442-456

Mencuccini M, Grace J (1995) Climate influences the leaf/sapwood area ratio in Scots pine. Tree Physiol 15:1-10

Notivol E, Garcia-Gil R, Alia R, Savolainen O (2007) Genetic variation in growth rhythm traits in the limits of a latitudinal cline in Scots pine. Can J For Res 37:54-551

Oleksyn J, Bialobok S (1986) Net photosynthesis, dark respiration and susceptibility to air pollution of 20 European provenances of Scots pine Pinus sylvestris L. Environ Pollut 40:287-302

Oleksyn J, Tjoelker MG, Reich PB (1998) Adaptation to changing environment in Scots pine populations across a latitudinal gradient. Silva Fenn 32:129-140

Oleksyn J, Reich PB, Chalupka W, Tjoelker MG (1999) Differential above- and below-ground biomass accumulation of European Pinus sylvestris populations in a 12-year-old provenance experiment. Scand J For Res 14:7-17

Oleksyn J, Reich PB, Rachwal L, Tjoelker MG, Karolewski P (2000) Variation in aboveground net primary production of diverse European Pinus sylvestris populations. Trees 14:415-421

Oleksyn J, Reich PB, Tjolker MG, Chalupka W (2001) Biogeographic differences in shoot elongation pattern among European Scots pine populations. For Ecol Manag 148:207-220

Oleksyn J, Reich PB, Zytkowiak R, Karolewski P, Tjoelker MG (2003) Nutrient conservation increases with latitude of origin in European Pinus sylvestris populations. Oecol 136:220-235

Peng C, Ma Z, Lei X, Zhu Q, Chen H, Wang W, Liu S, Li W, Fang X, Zhou X (2011) A drought-induced pervasive increase in tree mortality across Canada's boreal forests. Nat Clim Change $1: 467-471$

Poyatos R, Martínez-Vilalta J, Čermák J, Ceulemans R, Granier A, Irvine J, Köstner B, Lagergren F, Meiresonne L, Nadezhdina N et al (2007) Plasticity in hydraulic architecture of Scots pine across Eurasia. Oecologia 153:245-259

R Core Team (2015) R: a language and environment for statistical computing. R Foundation for Statistical Computing, Vienna, Austria. https://www.R-project.org/

Rehfeldt GE, Tchebakova NM, Perfenova YI, Wykoff WR, Kuzmina NA, Milyutin LI (2002) Intraspecific responses to climate in Pinus sylvestris. Glob Change Biol 8:919-929

Reich PB, Oleksyn J (2008) Climate warming will reduce growth and survival of Scots pine except in the far north. Ecol Lett 11:588-597

Reich PB, Oleksyn J, Tjoelker MG (1994) Seed mass effects on germination and growth of diverse European Scots pine populations. Can J For Res 24:306-320

Reich PB, Oleksyn J, Tjoelker MG (1996) Needle Respiration and nitrogen concentration in Scots pine populations from a broad 
latitudinal range: a common garden test with field-grown trees. Funct Ecol 10:768-776

Rigling A, Bigler C, Eilmann B, Feldmeyer-Christe E, Gimmi U, Ginzler C, Graf U, Mayer P, Vacchiano G, Weber P, Wohlgemuth T, Zweifel R, Dobbertin M (2013) Driving factors of a vegetation shift from Scots pine to pubescent oak in dry Alpine forests. Glob Change Biol 19:229-240

Seidel H, Menzel A (2016) Above-ground dimensions and acclimation explain variation in drought mortality of Scots pine seedlings from various provenances. Front Plant Sci 7:1014. doi:10.3389/fpls.2016.01014

Shutyaev AM, Giertych M (1997) Height growth variation in a comprehensive Eurasian provenance experiment of (Pinus sylvestris L.). Silvae Genet 46:332-349

Shutyaev AM, Giertych M (2000) Genetic subdivisions of the range of Scots pine (Pinus sylvestris L.) based on a transcontinental provenance experiment. Silvae Genet 49:137-151

Strasser BJ, Strasser RJ (1995) Measuring fast fluorescence transients to address environmental questions: the JIP test. In: Mathis P (ed) Photosynthesis: from light to biosphere. Kluwer Academic, Dordrecht, pp 977-980

Strasser RJ, Srivastava A, Tsimilli-Michael M (2000) The fluorescence transient as a tool to characterize and screen photosynthetic samples. In: Yunus M, Pathre U, Mohanty P (eds) Probing photosynthesis: mechanism, regulation and adaptation. Taylor and Francis, London, pp 443-480

Strasser RJ, Tsimilli-Michael M, Srivastava A (2004) Analysis of the chlorophyll fluorescence transient. In: Papageorgiou GC, Govindjee (eds) Chlorophyll fluorescence: a signature of photosynthesis, advances in photosynthesis and respiration, vol 19. Springer, Dordrecht, pp 321-362

Taeger S, Fussi B, Konnert M, Menzel A (2013) Large-scale genetic structure and drought-induced effects on European Scots pine (Pinus sylvestris L.) seedlings. Eur J For Res 132:481-496

Taeger S, Sparks TH, Menzel A (2015) Effects of temperature and drought manipulations on seedlings of Scots pine provenances. Plant Biol 17:361-372

Tilki F (2005) Seed germination and radicle development in six provenances of Pinus sylvestris L. under water stress. Isr J Plant Sci 53:29-33

Valladares F, Matesanz S, Guilhaumon F, Araújo MB, Balaguer L, Benito-Garzón M, Cornwell W, Gianoli E, van Kleunen M, Naya DE, Nicotra AB, Poorter H, Zavala MA (2014) The effects of phenotypic plasticity and local adaptation on forecasts of species range shifts under climate change. Ecol Lett 17:1351-1364

Vilà-Cabrera A, Martínez-Vilalta Galiano L, Retana J (2013) Patterns of forest decline and regeneration across Scots pine populations. Ecosystems 16:323-335 